\section{Mass Balance of the Cryosphere Observations and Modelling of Contemporary and Future Changes}

\author{
Edited by Jonathan L. Bamber \\ and Antony J. Payne \\ Cambridge University Press \\ 2004, 662 pages
}

Hardcover: ISBN 0521808952, \$140 US

\section{REVIEWED BY ROSS POWELL}

The recent monograph edited by Jonathan Bamber and Tony Payne is an excellent resource for those researchers wishing to learn about the status of the modern cryosphere and its influence on global climate and ice-ocean interactions. The editors should be credited with assembling a fine team of experts to make the assessments, which are presented in greater detail than those in Intergovernmental Panel on Climate Change (IPCC) reports. Those chapters involving the discussion of ice-ocean interactions are perhaps the most appealing to oceanographers, and therefore, are the focus of this review.

Chapter 1 (Bamber and Payne) sets the scene for the reader placing the relevance of the cryosphere in Earth's system and also evaluating it in a temporal and spatial perspective. After this introduction, the text is divided into five parts, each part representing a different general theme. If the reader is unfamiliar with the techniques used by glaciologists for these studies, then Part I-Observational Techniques and Methods will be helpful. This part includes Chapters 2, 3 and 4, which provide brief but competent overviews for how data are collected in areas of land-based ice (2-Hagen and Reeh) and sea ice (3-Wadhams). Useful assessments are also presented in these two chapters on pressing problems in data sets and in the appropriate algorithms used to represent natural processes in models. Chapter 4 (Bamber and Kwok) presents techniques used in remote sensing, including a review of the types of data sets available and techniques used in analyses. Discussions of data quality and coverage are helpful, although some advances have been made since the completion of this text.

Part 2-Modelling Techniques and Methods, includes three assessments, each warranting a separate chapter. The first chapter (5-Greuell and Genthon) in this section discusses modeling the mass balance of land-ice, describes how the surface energy balance is assessed and determined, describes how mass balance is modeled, and provides an assessment of the suitability of global climate models and their integration into cryospheric mass-balance studies. The discussion of modeling land-ice dynamics (6-van der Veen and Payne) starts with basic principles of ice flow, glacier dynamics and the parameters to consider in modeling. It next discusses the different approaches taken in modeling glacier dynamics and defines the critical parameters needed for the models. Importantly,

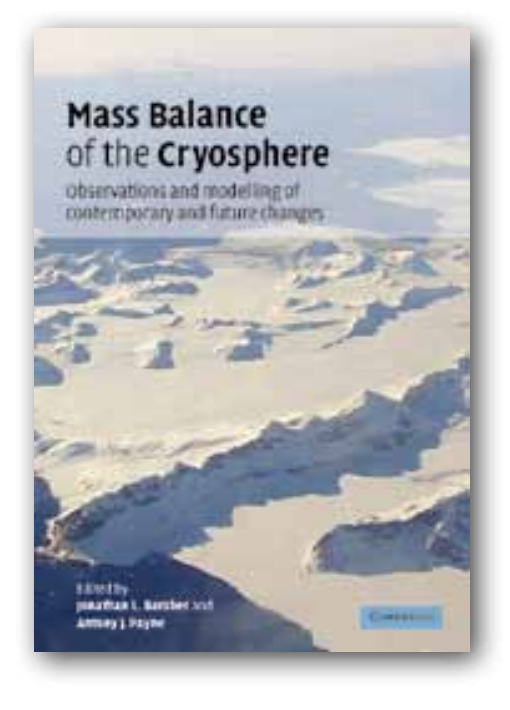

it also includes an unbiased assessment of the rigor to which the models approach reality. An extensive discussion is included on modeling the dynamic response of sea ice (7-Hibler) in the last chapter in the section. Background material about the of mechanical and physical behavior of sea ice provides the basis on which to, first, model sea ice drift and deformation; second, discuss sea ice mechanics and sea ice thermodynamics; and third, discuss the theories of ice thickness distribution. Chapter 7 ends with a thorough evaluation of the interplay between dynamic and thermodynamic models through simulations, model inter-comparisons and constraints provided by real data.

The last chapter of Part 2 provides a segue into Part 3-The Mass Balance of Sea Ice. Part 3 is divided into two chapters: one on observations (8-Laxon, Walsh, Wadhams, Johannessen and Miles) and the other on modeling (9Flato). This part is perhaps the weakest in the compilation. The observational chapter presents a pertinent synthesis of recent changes in sea ice. Although its total emphasis on the Arctic is appropri- 
ate due to current circumstances in the region, the lack of data on the Antarctic region is disappointing. As sea-ice modeling has been previously covered in Part 2 (Chapter 7), emphasis in Part 3 is instead placed on predictions and data assimilation into models.

Part 4-The Mass Balance of Ice Sheets, deals with assessments of the current mass balance of the world's major ice sheets through both observations and modeling. Chapters on observational mass balance in Greenland (10-Thomas) and Antarctica (12-Bentley) present relatively current and stimulating syntheses of data used to describe the current status of the world's largest ice masses. Problems that cannot be tackled because of lack of or poorly constrained data are clearly delineated, and future research paths are suggested. Some mention is made of the consequences on eustasy, but a thorough assessment is not presented in these chapters. An overview of consequences of the Antarctic ice sheets on sea level is provided in Chapter 13 (Huybrechts) where he discusses models that can be used to help predict possible future behavior of the Antarctic ice sheets. Similar, but less explicit, evaluations are presented for models of the Greenland Ice Sheet (11-van de Wal). Each modeling chapter evaluates model reliability relative to reconstructions of Pleistocene ice sheet histories and the geological data constraining them, as well as the degree of fit of the models to known modern conditions.

The mass balance of smaller ice caps and glaciers is dealt with in Part 5. It seems that the background review and monitoring strategies of such systems discussed in Chapter 15 (Haeberli) would more logically be the opening chapter of this section. Instead, Chapter 14 (Dowdeswell and Hagen) opens with an assessment of the observational mass balance of Arctic ice caps and glaciers. However, it primarily focuses on data from the Svalbard archipelago in an attempt to highlight the inherent problems in trying to generalize average net contributions of glacier melt to sea-level rise. The latter technique is used to its fullest extent in Chapter 16 (Dyurgerov and Meier) where annual mass balance re-

\section{Books Received for Review}

\section{Glaciers}

by Michael Hambrey and Jürg Alean, Cambridge University Press, 2004, 394 pages

Global Warming: The Complete Briefing

by John T. Houghton, Cambridge University Press, 2004, 382 pages

Physical Oceanography of Frontal Zones in the Subarctic Seas

by A.G. Kostianoy, J.C.J. Nihoul, and V.B. Rodionov, Elsevier Oceanography Series, 2004, 316 pages

cords from a global distribution of up to 90 glaciers (most located in the Northern Hemisphere) are used to assess net global balance and net contribution of these glaciers to $20^{\text {th }}$ century and modern sea-level rise.

The last chapter (17-Payne and Bamber) provides a summary, a synthesis, and an outlook for the future. It includes reviews of the mass balance of global sea ice, the Greenland and Antarctic ice sheets, Arctic ice masses, and global averages of smaller ice caps and glaciers. Brief reviews are presented of current uncertainties in both data and models. The book concludes by providing a guide to future research needs.

In summary, this volume presents a current scholarly assessment of the status and likely future changes in mass balance of the world's major ice masses. It provides sufficient background on techniques and model assumptions, and honest assessments of strengths of current data bases and model reliability. These techniques and assessments are described in such a way that any novice can gain a solid understanding of the reliability of predicted future changes in the cryosphere and its consequences. Oceanographers, especially those who study or model ice-ocean interactions, sea-level rise, or global circulation, would find this a useful reference text for their bookshelves, although at 85 pounds sterling ( $\$ 140.00$ US), some may urge its purchase by their library.

Ross Powell (ross@geol.niu.edu) is Distinguished Research Professor, Department of Geology and Environmental Geosciences, Northern Illinois University, DeKalb, Illinois, USA. 